\title{
Silvana Noemí Martínez: uma mirada latinoamericana e caribenha na FITS
}

\author{
Tânia Maria Ramos de Godoi Diniz*
}

Apresentamos aqui a entrevista realizada com Silvana Martínez, presidente global da Federação Internacional de Trabalhadores Sociais (FITS), gestão 2018-2022. Foram mais de três horas de um diálogo profícuo que ocorreu em dois momentos distintos. A FITS é uma instituição internacional que registra seus primeiros passos políticos em 1928 e, até 2018, quando ocorreu a eleição de Silvana, não havia tido um/a presidente oriundo/a da América Latina e Caribe. Conforme Silvana, essa eleição superou suas expectativas porque "no creía que una organización tan conservadora había puesto a una latinoamericana, feminista, con una ideología de izquierda como presidenta".

Silvana é argentina, nascida na cidade autônoma de Buenos Aires e, atualmente, professora titular da Universidade Nacional de Mar del Plata, responsável por uma cátedra que se chama Investigação em Trabalho Social I. Com uma formação autodidata marxista, suas análises e seus escritos não prescindem das miradas feministas e decoloniais, expressas em vários livros e artigos, dos quais é autora e coautora. Apreende-se de seus escritos as reflexões sistemáticas desenvolvidas sobre a dimensão política do trabalho social.

Em seus últimos textos vem refletindo sobre o trabalho social emancipador. Parte da premissa que o trabalho social deve ser antipatriarcal, anticapitalista e decolonial. Essa premissa se desdobra na defesa de três componentes fundamentais: a liberdade que implica a autodeterminação e independência, a autonomia que se traduz na soberania dos povos, e as condições históricas que trazem a materialidade para o trabalho social, sob determinações econômicas, políticas e culturais.

* Professora Adjunta do Curso de Serviço Social, Universidade Federal de São Paulo, Campus Baixada Santista. Representante do CFESS na FITS. Vice-Presidente da Região América Latina e Caribe, Federação Internacional de trabalhadores Sociais, gestão 2018-2022. E-mail:tgdiniz@uol.com.br. ORCID: https://orcid.org/0000-0003-3715-1438. 
Seu último livro, em autoria com Juan Agüero, "Trabajo Social Emancipador: de la disciplina a la indisciplina", critica "mucho la disciplina en términos de la concepción positivista de disciplina, de disciplinar la mirada, de disciplinar el ojo, de fragmentar los conocimientos, de fragmentar los saberes, de ver una realidad estática al sujeto que investiga o que interviene en ella, y eso de que el trabajo social en realidad tiene esa formación transdisciplinaria rompe, desborda eso... justamente para romper esta barrera ficcional del conocimiento y de la realidade".

Para o processo da entrevista, buscamos em Franco Ferrarotti (2007) as referências conceituais para apreender o nexo entre texto, contexto e intertexto. A narrativa de Silvana expressa uma experiência de vida em um determinado tempo histórico, o que impõe vincular essa experiência vivida às características contextuais do quadro histórico objetivo no qual ela se insere (FERRAROTTI, 2007, p. 33). ${ }^{1}$

Em outras palavras, como um sujeito político e historicamente determinado, nos eventos relatados no decorrer da entrevista, Silvana emite formulações políticas e teóricas que realimentam as relações estabelecidas entre história individual e história social e, ao expressar suas capacidades, dá materialidade à práxis. Para ela é nítido: "no podíamos abordar la realidade si no entendíamos el capitalismo y Marx fue la persona más lúcida de la historia del mundo para trabajar el capitalismo en la construcción del orden social."

Conforme Santos (2005, p. 62)2, "só é possível conhecer e compreender o indivíduo se apanharmos as particularidades socioculturais de um tempo histórico determinado". Nessa direção, afirma Silvana que "yo tengo, por lo menos, un enfoque histórico muy fuerte, no puedo ver la realidad sin un enfoque histórico, sin el enfoque más amplio, sin el enfoque político y sin ver estos dispositivos de poder que todo el tiempo están operando, en eso que Ilamamos el orden social... y que estos dispositivos siempre están operando, se van aggiornando, son más sutiles, van mutando con el capitalismo en sus distintas fases, con el patriarcado en sus distintas metamorfoseadas, pero que están vigentes, en términos de hilos conductores están ahí vigentes, siguen operando, sumado a el colonialismo y la colonialidad."

Durante a entrevista, em vários momentos, ressalta a "política como el gran ordenador social y también el gran instrumento de lucha, constitutivo del sujeto también. Todavía se sigue mezclando la política partidaria y la política y me parece que se ha mezclado bastante las militancias político-partidaria con la misión política que debía tener el trabajo social. Porque no se hablaba de un trabajo social emancipador, por lo menos acá en Argentina se hablaba de un trabajo social ideador, era entendido

\footnotetext{
${ }^{1}$ FERRAROTTI, Franco. Las histórias de vida como método. Convergencia. Revista de Ciencias Sociales, vol. 14, Universidad Autónoma del Estado de México núm. 44, mayo-agosto, 2007.

${ }^{2}$ Santos, Silvana Mara Morais dos. O pensamento da esquerda e a política de identidade: as particularidades da luta pela liberdade de orientação sexual. Tese de Doutorado. Recife: UFPE, 2005
} 
en clave humanista cristiana, tampoco era clave política y menos teniendo en cuenta las otras dimensiones que tienen que ver con la construcción histórica de la región. Yo siempre le digo si no entienden de política y poder no entienden nada de trabajo social porque justamente son dos grandes categorías que construyen el orden mundial y el trabajo social se inserta en esas relaciones sociales, en este mundo capitalista patriarcal, y en este caso desde nuestro lugar colonialista".

Quanto as relações de poder, Silvana salienta os elementos centrais: "estamos siempre atravesados por esos grandes dispositivos de poder en términos de sometimiento, tanto el patriarcado, como la colonialidad (no colonialismo porque supuestamente nosotros no somos colonia) y el capitalismo...porque me parece que el trabajo social tiene que tener esa mirada, independientemente del lugar donde esté trabajando, más estructural de los problemas sociales, porque si no, nos quedamos en respuestas más inmediatistas, nos quedamos en la superficie de los problemas y no vamos a la raíz."

Organizamos o conteúdo transcrito da entrevista destacando de partida alguns elementos que referenciam o lugar político ocupado por Silvana, como presidente da FITS. A seguir, solicitamos-lhe que falasse de sua trajetória acadêmica profissional, as motivações que configuraram a profissão na sua vida. Pedimos-lhe, posteriormente, que destacasse eventos políticos na região da América Latina e Caribe e internacionalmente, suas fricções e tensões. Finalmente, solicitamos que socializasse suas impressões, a partir do lugar de presidente global, sobre as tendências do Serviço Social na atualidade.

Como presidente global da FITS, a primeira da América Latina e Caribe em todos os anos de existência da FITS, poderia nos dizer alguns dos desafios e conquistas de uma gestão que tem se posicionado criticamente diante das demandas que têm surgido?

"Empezamos a cambiar las dinámicas de las reuniones entre los miembros de FITS, esto que nosotros vemos ahora dista mucho de lo que yo conocí en el 2014 donde no había debate, no había enfrentamiento, no había nada porque era una escribanía, se iba a convalidar cosas que ya se habían decidido por otro lado. Inclusive en las asambleas casi no se debatía tampoco, ese primer gran debate fue en el 2012, en la asamblea de Estocolmo.

Empezamos a instalar la mirada política del trabajo social, la necesidad de hablar de las causas de los problemas sociales, porque siempre se hablaba de las consecuencias, y como era un trabajo social apolítico, global, pero vacío, como un globo de aire, sin inscribirlo en contextos históricos concretos.

Después, eso otro de fortalecer a las regiones, había como un Secretario General muy fuerte, y regiones bastante debilitadas y abandonadas, 
excepto Europa porque además tiene sus recursos propios, tienen otra forma de organizarse, así que eso también fue un poco de democratizar y fortalecer los liderazgos regionales. Entonces también mi compromiso fue no hacer lo mismo que hicieron los otros presidentes históricamente con nosotros, así que por suerte pude estar en todas las regiones al menos una vez para tener esta oportunidad, de generar este debate, de llevar esta postura, esta voz de la región y también aprender un poco de lo que se estaba haciendo a nivel mundial.

También logramos esta Conferencia Global gratuita (julio de 2020), no arancelada, esa también logramos con la democratización de la participación.

Ya la construcción con las escuelas, a mí me parece fundamental, porque además la formación es clave para el trabajo social. La relación con las escuelas (Asociación Internacional de Escuelas de Trabajo Social/ AIETS) estaba totalmente fragmentada y además la relación se planteaba en términos de competencia en vez de complementariedad y de colaboración, entonces era "¿cuál organización es más importante?", y costó mucho porque había mucha desconfianza.

Por suerte con Annamaria Campanini (presidenta de la AIETS), hicimos una muy buena relación, aunque ella trabaja el trabajo social sistémico y yo estoy en la antítesis, más allá que tenemos distintos enfoques, tuvimos una muy buena relación para volver a construir esta confianza. Decíamos "tenemos que acompañarnos, tenemos que hacer crecer juntos, me parece que la voz a nivel internacional tiene que estar fuerte ante la barbarie neoliberal". Nos pusimos de acuerdo en muchas cosas, también con el Consejo Internacional de Bienestar Social. (CIBS)"

Y el tema de las condiciones laborales, hay que debatir en ámbito regional e internacional. Principalmente con el tema de la pandemia de Covid-19, la FITS busca conocer a los/las trabajadores/as sociales que tuvieron que revisar su trabajo con grupos y comunidades en diferentes regiones del mundo".

\section{Fale-nos sobre sua trajetória acadêmica profissional. É importante que ressalte as motivações, os parâmetros e perspectivas que orientam o trabalho social para você e que investimentos teve que fazer na formação que configuraram a profissão na sua vida.}

"Fue en el año 1997, cuando yo comencé el primer año en la Universidad Nacional de Misiones, en la Facultad de Humanidades y Ciencias Sociales. ¿Qué pasaba en la Argentina? Pleno neoliberalismo, la segunda década infame, como la llamamos nosotros. Tuvimos una década infame de la burguesía y la oligarquía terrateniente, de 1930 al 1940 y a esta se la Ilamó la segunda década infame, porque fue una década de entrega del país, una época de privatizaciones de los servicios públicos. 
Una época donde el Estado jugó abiertamente para las corporaciones transnacionales de apertura y de regulación de la economía, incluso querían privatizar la Universidad Pública Argentina, que acá es gratuita, es pública y no se paga un peso, no arancelada desde el año 1945 con el peronismo, y siempre fue como un bastión de resistencia. Intentaron arancelarla, privatizarla, ahí salimos todos los estudiantes y docentes de las universidades del país y el Ministro de Economía duró tres días, él que quería privatizar, se tuvo que ir. Pero fue una época muy triste donde las escuelas ya no eran para formar sino para darle de comer a los niños, cierres masivos de empresas, despidos masivos, así que bueno, volvimos a las ollas populares.

Llegamos a más de $50 \%$ de la población por debajo de la línea de pobreza, en situación de pobreza, endeudamiento externo enorme, digamos toda la receta del Consenso de Washington. Bush, que estaba como presidente de EUA, elogió a la Argentina que era el mejor alumno, el alumno ejemplar, así que tuvimos relaciones carnales con los Estados Unidos.

Después llegó a la crisis del 2001, donde hubo 30 compatriotas muertos, argentinos muertos manifestándose en la plaza, hubo saqueos de supermercado, la gente no tenía para comer, había una desesperación total, así que fue un momento muy difícil.

La carrera duraba 5 anos, empecé en el 1997 y me gradué en el año 2002, o sea después de toda la crisis que explotó la Argentina, de 19 y 20 de diciembre del 2001, donde en término de una semana pasaron 7 presidentes. El pueblo decía "iqué se vayan todos!", absolutamente ingobernable la Argentina en este momento.

Primero, lo que tengo que decir es que fue una formación horrible la que yo tuve de base de grado, una formación positivista, una formación alejada de la realidad, no politizada, aunque tenga leído Chomsky y textos sobre problemática de género en quinto año. La carrera parecia estar como en una burbuja, porque no daba cuenta de esta realidad que estaba pasando afuera. No había movimiento estudiantil y no lo hay hasta el día de hoy.

Como estudiante, yo también empiezo a participar en las organizaciones profesionales, en el Colegio de Servicio Social de Misiones, porque necesitaba poder encontrar otro lugar de construcción colectiva. Y mientras estudiaba, militaba políticamente porque creo que, más allá del contenido teórico y de la formación, la realidad se transforma desde la política y lo político, así que empecé a militar políticamente por muchos años yendo a los barrios, haciendo tareas barriales, concientización, formación, capacitaciones donde había movimientos populares y sociales y organizaciones.

O sea, mi ejercicio profesional estuvo vinculado a violencia familiar, intrafamiliar, abuso sexual infantil, violencia hacia las mujeres, ahí trabajé mucho y también me di cuenta que me faltaba formación para poder abordar seriamente esa problemática que era muy compleja. 
Empecé a trabajar en el 2003, ahí voy al Congreso Nacional de Trabajo Social en Tandil, provincia de Buenos Aires. Fue mi primer congresso y presenté mi primera ponencia sobre Paulo Freire. Yo ya me había graduado cuando conocí a Paulo Freire y Alfonso Ibañez (peruano que estudió también la educación popular) y empecé a encontrar otro mundo. Ahí estaba Margarita Rosas, Sela Sierra (pioneira del trabajo social de Argentina, bastante avanzada y politizada) y ahí también, conozco a José Paulo Netto por primera vez, escuché su nombre y su postura, digamos, totalmente desconocida, porque nunca se lo había mencionado en la carrera, no sabía la cuestión social de qué se trataba. Hasta el día de hoy pasa eso en la facultad de Misiones, no son textos que se dan, no son textos que se trabajan. Nunca se ha politizado la formación, nunca se hablaba de política, ni del contexto, hasta el día de hoy sigue una dicotomia muy fuerte entre teoría y práctica.

Empecé a cursar la maestría en trabajo social en el año 2004, en la Universidad Nacional de Entre Ríos. En el 2009 defendí la tesis y me recibí de magister en trabajo social. Tuve que volver a desconstruirme y construirme nuevamente, porque mi tesis fue sobre los procesos de dominación y emancipación de mujeres en contextos de violencia familiar. Yo redefino la violencia y la abordo desde el famoso ciclo de la violencia de Leonor Walker (1979) utilizado para identificar patrones abusivos en una relación afectiva, pero planteo la violencia como un proceso dialéctico entre la emancipación y la de dominación. En realidad, despues la publiqué como libro, el libro se llama "Sueños rotos, vidas dañadas: violencia hacia las mujeres en contextos familiares" (2009).

Me anoté ese mismo año en el doctorado de Ciencias Sociales también de la Universidad Nacional de Entre Ríos que he terminado en 2012. Hice tesis sobre los partidos políticos, porque también me atravesaba la política y lo político y me atravesaba lo del feminismo. El primer feminismo que yo me formo es el feminismo eurocentrado, académico, burgués, blanco, el feminismo clásico. Esa fue la primera formación, después empecé a entrar en otros mundos, de otras lecturas y quise mostrar la persistencia de las desigualdades de género en los partidos políticos más importantes de Argentina, que es la Unión Cívica Radical y el Partido Justicialista, dos partidos centenarios, los más históricos y tradicionales. Y lo que yo quería mostrar es que más allá del avance normativo, de la ley de cupo, de los discursos, de la retórica, las mujeres estaban en las grandes bases haciendo el trabajo territorial mientras quien tomaba las decisiones y conformaba las listas eran los varones. Y que eso no tenía nada que ver con un partido político en específico, sino en como se entendía la política, donde todavía seguimos siendo vistas como las "recién llegadas", porque el espacio privilegiado de lo público, de la política y lo político todavía muchos conciben que son de los varones y tenemos que hacer un esfuerzo extra para ver si somos merecedoras de estar en este lugar. 
Empecé a trabajar esa mirada del trabajo social emancipador, porque era una dimensión invisibilizada, se hablaba de la dimensión politeórica, metodológica, pero nada de política, nada de ideología. La definición de proyecto ético-político, lo escuché mucho después. En el 2008, escribí con Juan Agüero "La dimensión político-ideológica: claves para un trabajo social emancipador", porque aparecía la emancipación como algo que me resonaba y que estaba ahí, muy fuerte.

Obviamente al salir de la provincia, de la Universidad de Misiones y empezar a tener contacto con universidades de Brasil, de Chile, ahí empecé también a abrir mi mirada y a leer otras cosas y estar en contacto y demás, me fui también a Paraguay, tuve un fuerte contacto con Paraguay, ahí con la colega Stela Maris García Agüero, que también se formó en Brasil (su tesis, la publicó como libro que se llama "La Cuestión Social en el Paraguay del siglo XX: trabajo social y políticas sociales (2019)").

Pero, realmente, la formación no fue buena y después tuve una formación variada, pero fui seleccionando lo que yo quería. De manera autodidacta estudié Marx (acerca de la construcción del orden social del capitalismo), Atilio Borón (que abrió un enorme campo de visibilidad en la lectura del neoliberalismo y del marxismo), Josef Estermann (con quién estudié filosofia decolonial andina). Todas esas lecturas fueron como influyendo en mí y después empecé a transitar por lecturas de los feminismos decoloniales, poscoloniales, los feminismos del sur y el feminismo comunitario de los pueblos originarios, que también se me abrió otro mundo, incluso los feminismos comunitarios critican a los feminismos decoloniales porque el feminismo decolonial empieza la historia en 1492 y el feminismo comunitario dice "nuestra historia no empezó en 1492, tenemos una ancestralidad que ustedes la están negando".

Hoy estoy en la docencia y estoy dirigiendo un proyecto de investigación que se llama "Feminismos del Sur e intervención social: genealogías, diálogos y debates". Yo entiendo la docencia como ejercicio de la profesión y, así como colegas que trabajan en salud, en justicia, yo trabajo en el ámbito de la universidad pública, en el ámbito de la organización superior universitaria. Mi ejercicio profesional es ahí, ese es mi territorio, estos son mis sujetos de intervención, y ese campo de la reproducción simbólica, ideológica, ético-política, teórica y epistemológica es muy importante. Así que yo lo veo como un espacio de lucha al igual que las organizaciones profesionales que, más allá de la formalidad o lo que te pide una ley, son espacios de legitimación, son espacios de construcción colectiva, son espacios de reconocimiento, son espacios de lucha, de posicionamiento, así que siempre defiendo estos espacios".

Acerca do significado e alcance do trabalho social, Silvana tem preocupações com a formação profissional na Argentina e em outros países da América Latina e Caribe. 
"En general en la universidad pública la carrera dura 5 años. Y acá se intentó, - creo que desde la FAUATS - Federación de Unidades Académicas de Trabajo Social - hacer eso que tienen en Brasil, de consenso de mallas básicas de plan de estudios, porque si no parece que estamos formando personas en países distintos. La verdad que se hizo ese esfuerzo, pero claro, depende después de cada carrera trabajar hacia el interior de su cuerpo docente para que hagan estos acuerdos y poder implementar, inclusive ponerse de acuerdo en términos de debates, explicitar desde qué uno piensa, de por qué este autor y no otro - que no se hace tampoco.

Entonces, en general, es una formación bastante ecléctica y costó mucho para implementar los consensos mínimos de esa malla curricular básica para todas las carreras del país. Así que, sumado a que acá tenemos lo que es formación superior no-universitaria, los terciarios, carreras de pregrado. Después están las universidades privadas, y después también tiene la impronta muy fuerte confesional. Todavía hay formación a distancia, aunque muy poca. Acá hay un posicionamiento de FAAPSS contra la formación a distancia. Tenemos una carrera en la universidad pública en el sur de la Argentina, en Río Negro, donde tenemos una formación virtual. Es la única del país porque son miles y miles de kilómetros de distancia, entonces tienen una parte presencial y una parte virtual.

Ahora también está como consolidándose lo del trabajo social clínico, que me preocupa bastante también porque, si bien lo dan en la formación, no es algo que estaba como instalado en el colectivo profesional. Por ahí se dan el sistémico, el clínico, pero no era algo que se veía como un campo laboral. Ahora, con eso de la virtualidad, porque también antes no estaban las redes sociales, entonces veo que aparece muy fuerte en Chile, aparece muy fuerte en España, ya estaba en Puerto Rico, ha entrado también en El Salvador, entonces eso está generando influencia y eso sí me está preocupando porque veníamos como resguardados en esto, nosotros veníamos como zafando de esa postura, pero ahora a partir de las redes que se van formando, de estos cursos de posgrados virtuales, es como que lo están mirando desde distintas maneras y aparece como más fuerte.

Y además hay una cisión también, con los docentes que no se identifican como trabajadores sociales ni como trabajadores asalariados, "soy investigador, soy doctor, soy magíster", hay una cisión enorme pero en realidad es también un tema absolutamente vedado en la formación, una formación apolítica, una formación ecléctica, una formación sin la vinculación con el ejercicio profesional, las organizaciones profesionales, y en ese sentido, la que tiene una definición como mucho más clara es la de Tandil, que tiene una formación marxista, más lukacsiana, pero es la única que más o menos tiene como una definición en su malla curricular y en la maestría también, pero el resto es como también en realidad un eclecticismo, pueden dar Bourdieu, como dar Foucault o Ander Egg, es lo mismo. 
Y me parece que el trabajo social debe tener en cuenta las dimensiones sociales, económicas, políticas a la hora de pensar estrategias de intervención más coyunturales, pero pensando en transformar la realidad a mediano y largo plazo, transformar el orden social, no solos, pero sí aportando cada uno desde sus lugares, construir otras subjetividades, construir fuerzas colectivas, poder popular, conciencia. Yo siempre veo cuando hablo de conciencia, me refiero a la conciencia histórica de Marx, me refiero a la conciencia feminista, me refiero a la conciencia de clase, a esta conciencia que hay que trabajarla y mucho porque la formación es tan débil que cualquier cosa de moda es capturada"

A partir dos eventos relatados, como o caminho teórico acadêmico profissional contribuiu com o desenvolvimento do trabalho político realizado em Argentina, como presidente da FAAPSS, na América Latina e Caribe, como presidente Regional da FITS e na Federação Internacional de Trabalhadores Sociais, como presidenta global?

"Después de la formación, fui a matricularme en el Colegio de Profesionales de Servicio Social de Misiones, siempre tratando de aportar desde la construcción colectiva. Era un colegio prácticamente inexistente, nadie quería participar. Si bien tenemos por ley provincial la obligatoriedad de la matrícula, nadie la cumple.

En 2002, empecé a participar de la Federación Argentina de Asociaciones Profesionales de Servicio Social y a poner el debate político, a cuestionar este espacio nacional que no se hablaba de temas socialmente significativos, que la Federación no tenía una voz nacional en los problemas sociales y políticos. A partir de ahí también fuimos instalando el debate acerca de la dimensión política, ideológica y ética de la profesión, y fue tal la influencia que, en el año 2007, el Congreso Nacional, en Mendoza, fue sobre la dimensión política del trabajo social. Entonces los colegas reconocían que estaban como adormecidas de un proceso que después de la dictadura cívico-militar no habían recuperado ese debate político, quedaba más en lecturas coyunturales, en problemáticas más provinciales, cosas más locales, sin ver el proceso histórico y el lugar político de la Federación.

Ahora somos 25 colegios en la Federación, ahora están todas las provincias, no estaban todas las províncias en 2002, ese fue un proceso que lo hice yo durante mi presidencia porque es una filiación voluntaria, porque lo que te obliga la ley es matricularte en tu colegio provincial para ejercer la profesión, pero la Federación es una organización de segundo grado, es una asociación civil donde los miembros son los colegios, no las personas y la afiliación es voluntaria.

Me eligieron presidenta de la Federación en julio del año 2010, justo se hizo el Congreso Nacional en Misiones, con el tema de "Los aportes del Trabajo Social en los procesos de emancipación social", o sea, 
empezamos a tener congresos más politizados, a hacer pronunciamiento, no solamente una instancia de conferencias y ponencias, sino que también se constituye en un acto en sí mismo político.

A partir de ahí, de esta presidencia, yo me propuse fundamentalmente tres cosas: constituir a la FAAPSS como un actor político social de relevancia a nivel nacional, o sea que tenga injerencia, que tenga voz y que tenga presencia en el debate nacional, en los medios de comunicación. Me propuse la Ley Nacional de Trabajo Social que finalmente quedó como Ley Federal de Trabajo Social no 27072. Y me propuse el cambio de día del trabajador social en Argentina que era el 2 de julio, que lo habían puesto colegas que pertenecían a la Unión Católica Internacional de Servicio Social, la UCISS.

En la década de 1960, mira la contradicción, en plena época de reconceptualización, se pone el 2 de julio como el día del trabajador social, porque quienes manejaban tanto a la academia como las organizaciones profesionales eran colegas que estaban vinculadas a la religión católica. Como veníamos de ser visitadoras médicas, visitadoras de higiene, creyeron que sería el que más nos identificaba, el día que la Virgen María va a visitar a su prima Santa Isabel y anuncia que está embarazada. Fue un estigma conservador y religioso en nuestras espaldas, inclusive en algunos colegios hacían misas hasta hace poco. Hay dos provincias que lo siguen sosteniendo, o sea, hay una fecha nacional y ellos dejaron su fecha provincial y siguen sosteniendo el 2 de julio como el día del trabajador social.

La primera ley de trabajo social de Argentina fue sancionada en Misiones en 1964 y la última ley provincial se sancionó en la provincia de Corrientes en el 2014, entonces durante todo este proceso se sancionaron leyes con distintas concepciones de trabajo social y distintas incumbencias. Entonces yo les decía "necesitamos una ley que fije incumbencias nacionales, una ley que proteja las condiciones laborales" porque es otro tema importante, fue organizada una comisión de condiciones laborales porque tampoco se hablaba de esta situación en la Federación.

La verdad que este proyecto, que ahora es ley, se sancionó en el Senado de la nación por unanimidad, así que para nosotros fue una conquista histórica de una lucha que ya venía de la década del 1960, de estos colegas que se habían propuesto la necesidad de una ley nacional, de formar a los colegas en el tema de la agremiación, de concientizar la importancia del gremio, todo eso se planteaba en la década del 1960 pero no tuvo influencia ni en la academia, ni en los colegios en este momento. Así que fue, de alguna manera, como recuperar ese legado.

El otro fue el cambio del día nacional porque lo sustentamos el 10 de diciembre como el Día Internacional de los Derechos Humanos, pero más allá de la visión liberal de los derechos humanos, de la ONU, nosotros le dimos nuestra impronta que tiene que ver con la historia de Argentina, con la última dictadura cívico-militar, de alguna manera también reivindicar 


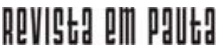

\} SILVANA NOEMÍ MARTÍNEZ - DINIZ, T. M. R. G. \}

DOI: 10.12957/REP.2021.60311

la lucha de estudiantes y colegas torturados, desaparecidos, exiliados que lucharon por la democracia, que lucharon por los derechos humanos, reivindicar esa lucha por las abuelas y las madres de Plaza de Mayo y que, como trabajadores sociales no podíamos estar desvinculados a esas luchas populares que nos identifican como pueblo en la Argentina, en el mundo. No fue fácil cambiar la fecha, pero cuando finalmente se votó, fue prácticamente por unanimidad. Solamente una provincia se abstuvo, es muy católica.

Así que, a partir del 2012, ahora celebramos el Día del Trabajador y Trabajadora Social en Argentina el 10 de diciembre, y justo fue el día que además se sancionó la Ley Federal de Trabajo Social.

En 2010 ya empecé a tener contacto, como presidenta de FAAPSS, con el Comité Mercosur, ahí empieza mi contacto latinoamericano e internacional. En el Comité Mercosur, ahí las conozco a Samia Rodrigues Ramos y a Esther Lemos (en 2011), con anterioridad, a Rosa Stein. Mi primera reunión me acuerdo que la tuvimos en Asunción, Paraguay, estábamos representantes de Argentina, Brasil, Chile, Paraguay y Uruguay. Brasil y Argentina veníamos con la misma propuesta de una revisión del estatuto del Comité Mercosur, del rol que tienen que cumplir las organizaciones profesionales. Eso como que se había perdido con el transcurso del tiempo, quizá lo tuvo en algún momento cuando se opuso a la definición internacional del trabajo social en el año 2000 en Monterrey.

Estábamos en este proceso y en el 2011 se hace el encuentro de la región de América Latina y el Caribe, que hacemos siempre desde la FITS, en Argentina, en la provincia de Mendoza. Vino Estela Barreto, de Puerto Rico y planteó que Puerto Rico hacía años que venía luchando por la incorporación a la FITS y que Estados Unidos no quería, porque lo consideraban que era parte de Estados Unidos. Ahí había representantes de los países, estaba Bolivia, Perú, Chile, Brasil, entonces la causa de Puerto Rico pasó a ser nuestra causa e hicimos un pronunciamiento, firmamos todas las organizaciones nacionales que estábamos y se lo dimos a Rory (secretario general da FITS) para que se lo presente a la presidenta de la Asociación Norteamericana de Trabajo Social.

El otro tema que teníamos, que empezamos a discutir, y que se estaba discutiendo en ese momento era la definición mundial de trabajo social. O sea, teníamos esas dos causas para trabajar y ahí también en el marco de nuestra reunión de FITS, tuvimos nuestra reunión del Comité Mercosur, los colegas de otros países pidieron autorización para estar presente y ahí manifestaron la necesidad de ampliar este espacio al resto de países de América Latina.

Ahí surge la idea de COLACATS, del Comité Latinoamericano y Caribeño de Organizaciones Profesionales de Trabajo/Servicio Social. Lo discutimos bastante, si era viable, si no lo era, si convenía, y estuvimos de acuerdo que sí, que necesitábamos sumar más voces, que si sumábamos 
más voces en la región, podríamos también tener como más peso específico a nivel internacional en las asambleas, en las luchas.

En 2013, en Montevideo, se trabajó un documento fundacional de COLACATS donde se tomaron los principios éticos-políticos que se habían construido para el Comité Mercosur de Organizaciones Profesionales de Trabajo/Servicio Social, que fue un documento importante y que sigue siendo, un documento político, un documento que orienta la acción, la lucha, la organización colectiva. Entonces nosotros creíamos que teníamos que seguir sosteniendo estos principios éticos-políticos y hacer como un acto refundacional, ponerlo como un antecedente de este COLACATS y ahí se eligió la coordinadora, que fue la primera coordinadora del Comité, Esther de Souza Lemos (2014-2017).

Y ahora el COLACATS se mimetizó con la región de la FITS y se perdió su propia identidad, su autonomía, o sea de hecho todos los pronunciamientos que hicimos nosotros los hizo la FITS y le ponemos el logo de COLACATS, pero en realidad no ha surgido nada al revés de COLACATS.

Creo que hay que pensar eso, su autonomía, su agenda propia, trabajar juntos pero que no se mimetice porque, además, lo bueno de COLACATS es que no tiene que pagar cuota, hay más espacios de libertad que depender de una organización internacional que a su vez tiene reglas o estatuto, que te va marcando de alguna manera algunos límites. Entonces este espacio de autonomía me parece que hay que recuperarlo, recuperar el espíritu de este momento, de por qué se fundó y por qué era necesario y que trabajen las organizaciones juntas, pero no mimetizadas.

El 2012 me fui a Estocolmo y fue mi primera asamblea mundial, fue también ya como presidenta de FAAPSS. Ahí tuve contacto con esta Federación Internacional de Trabajadores Sociales y ahí había dos grandes temas a tratar: la definición mundial y la incorporación de Puerto Rico.

Para la definición mundial, anteriormente en marzo de 2012, CFESS organiza un workshop que nos invita a todos los miembros del Comité Mercosur y algunos colegas más, estuvo también Rory Truell (el secretario general), estuvo el coordinador general de la Comisión de Definición que es Nicolai Paulsen, estuvo Abye Tasse por las escuelas de Trabajo Social, estuvo Lorena Molina por la ALAEITS. Un encuentro muy interesante y Brasil ya había empezado a instalar este cambio de definición mundial, y había hecho la estrategia de repartir las definiciones y nos dieron la tarea de discutir eso en nuestras organizaciones y hacer después el workshop en Río de Janeiro.

La verdad que esos dos o tres días fueron de debate y pudimos articular una estrategia política y poder consensuar una definición como región. También ahí empezamos a darnos cuenta que no podíamos fragmentarnos porque sino la lucha a nivel internacional no iba a tener fuerza. De hecho, después yo hice toda una historia de la influencia que había tenido a nivel internacional la región de América Latina y el Caribe y en las 
asambleas teníamos 4 votos, 3 votos, 6 votos, era nada; por eso también nunca fuimos escuchados y fuimos tenidos en cuenta. Obviamente también por la dificultad financiera de bancarse estos viajes y estar al día con la cuota.

Entonces, creo, eso permitió organizar un proyecto ético-político nuestro, propio, genuino, se generó un clima de camaradería y de lucha colectiva. Entonces todos estábamos unidos en la causa y ahí nos fuimos a pelear con nuestra definición de región a Estocolmo. Todavía teníamos seis votos nada más en esta asamblea, pero fue tan fuerte la presencia y la insistencia, y ellos querían imponer otra definición que no nos seguía convenciendo entonces al final se pasó para el 2014, no se tomó ninguna decisión, no había consenso, pero nos quedaba lo de Puerto Rico.

Ahí fue como una antes y una después para América Latina en la FITS. Ahí empezaron a decir que existe esta región que viene con mucha fuerza, teniendo solamente 6 votos. Fue tal el argumento político que convencimos al resto y logramos cambiar la historia. También ahí pudimos mostrar como la lucha es colectiva, porque Puerto Rico lo intentó en soledad por muchos años, hizo muchas presentaciones, hasta que se tuvo que sumar y pudimos articular y pudimos asumir una lucha colectiva y pudimos ganar.

En la región, al principio había una fragmentación entre los de Centro América y América del Sur, había mucha desconfianza, se creía que nosotros veníamos a imponer algún tipo de trabajo social. Porque el Comité Mercosur es el que vino construyendo el trabajo social latinoamericano, con sus dificultades, pero en otros lados no había nada, el único que había conformado al menos un espacio y lo había sostenido a lo largo del tiempo fue el Comité Mercosur.

Después yo creo que se fue diluyendo esos temores, de hecho todos los temas que fuimos aprobando, que se fue discutiendo, se fue consensuando, incluso hasta las candidaturas. Todo lo que fue surgiendo de ahí fue producto de un consenso, un debate colectivo, donde se pensaba quién era que tenía el mejor perfil para ocupar los cargos. La verdad que se construyó un grupo muy consolidado. Todas las propuestas y las candidaturas para todos los puestos que hay en la FITS, todo se fue discutiendo y teniendo el aval de los países. Así que eso fue un cambio importante y también la visibilidad a partir de los pronunciamientos políticos".

A seu ver, como presidenta global, quais são os principais desafios para o trabalho social no mundo? Quais são as tendências, sejam conservadoras, sejam emancipatórias, que tem visto acerca do trabalho social nas diferentes regiões do mundo?

"En Región de África, lo que vi es un trabajo social basado en la comunidad, un trabajo social comunitario, pero desde una perspectiva de 
los Organismos Internacionales. O sea, toda la línea que acá llegó en Argentina en el desarrollismo, en la década del 1950/1960, todas las prácticas y el instrumental metodológico y teórico que tienen los colegas de África vienen de Organismos Internacionales y de Asociaciones no Gubernamentales, de ONGs, donde obviamente no pasa por ningún lado el hablar de racismo, ni de feminismo, ni de decolonialidad, ni colonialidad, ni postcolonialidad.

O sea, es un trabajo social muy colonizado y dependiente de las organizaciones gubernamentales, basada en la ayuda y con una sumisión terrible donde les agradecen a esos organismos internacionales, que pueda darles esa ayuda económica. Hacen esas prácticas comunitarias, pero desde esas lógicas y programas que vienen de Naciones Unidas, de UNICEF, de organizaciones de mujeres, pero que no tienen una mirada propia del trabajo social mucho menos política, mucho menos económica, ni histórica.

En Región de Asia y Pacífico, me fui a Japón y también vi un trabajo social tecnocrático, un trabajo social más basado en la psicología. Ellos hablan mucho de la resiliencia, con problemáticas de salud mental muy fuerte que tiene que ver con el hiperindividualismo en el cual se encuentran; dónde hay gente que nunca salió de su casa, y a veces son personas que ni siquiera salen de su cuarto y no interactúan con los miembros de la familia, es una problemática muy generalizada. Ellos no problematizaban, o sea lo hablaban como un problema de salud mental y lo abordaban desde qué hacen con que estos sujetos en términos de pensión cuando los padres de esta gente no tienen más quien los atiendan, o cuando se enfermaban, o la vergüenza que daban, o el honor de la familia, no vinculaban con eso del neoliberalismo.

Pero lo que vi sí es una fuerte reivindicación de los pueblos indígenas en Nueva Zelanda, eso está muy fuerte, poder recuperar y visibilizar esos saberes de los pueblos originarios indígenas, o como le dicen ellos "los primeros pueblos".

Después en Europa, veo dos líneas, una que es el de trabajo social radical y crítico, que antes era súper marginal pero que fue como creciendo, en términos de producción de conocimiento y creciendo en esto de la red de acción social de trabajo social crítico que se termina de armar (SWAN).

Pero, todavía hay sí en Europa un trabajo social conservador y un trabajo social basado fundamentalmente en la prestación de servicios sociales, pero solamente desde un lugar de prestar servicios público-estatales. No hay un desarrollo tampoco teórico de problematizar esos problemas y sujetos que vienen a los servicios sociales. También están muy fuertes en ese trabajo social las organizaciones no gubernamentales, desde ahí consiguen fondos, pero son proyectos que son de centrarse más en lo metodológico y de tratar de organizar la vida social, no de disminuir eso y plantear la justicia social, no se plantea distribución de la riqueza. 


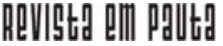

\} SILVANA NOEMÍ MARTÍNEZ - DINIZ, T. M. R. G. \}

DOI: 10.12957/REP.2021.60311

En América del Norte, tienen un trabajo social clínico, un trabajo social psicologicista, biologicista, individual, siguen con el caso social individual, el caso clínico, mimetizado con la psicología y atendidos desde consultorios. En general el trabajo social de Estados Unidos es un trabajo social absolutamente apolitizado, individualista, biologicista y psicologicista, psicologizan el problema social, no lo ven como problemas sociales, lo ven como problemas individuales. Hay algo bueno que hizo Trump, es que despertó de vuelta esta mirada más política del trabajo social en Estados Unidos, en la relación a las migraciones, a como trataban a los niños separados de sus padres mexicanos, aparece muy fuerte eso de la racialidad.

En la región de América Latina y el Caribe, hay mucha heterogeneidad dentro de nuestros países. Hay avances y retrocesos, esa tensión permanente y a mí me preocupa porque hacemos un paso para adelante, tres pasos para atrás, por eso es clave quién esté liderando las organizaciones profesionales. Yo veo nuestros países de la región con mucha debilidad teórica, tienen mucha fuerza de voluntad, pero no tienen la formación, ni un posicionamiento claro.

Tenemos que estar muy atentos para tener claridad en estas matrices teóricas, epistemológicas, políticas, ideológicas que sustentan un trabajo social. Entonces yo veo muy buena voluntad, muy buena gente nuestros compañeros, pero una formación muy débil. ¿Qué trabajo social queremos por la región de América Latina y el Caribe? ¿Cuál es el camino que construimos? ¿Y hacia dónde queremos continuar?

En Ecuador, la formación es apolitizada, lo máximo que ven en el grado de la formación básica es Mary Richmond y Ander Egg. En Chile, es un trabajo social en general tecnocrático y aséptico, pero hay ahora una masa crítica de un trabajo social crítico, apareció con fuerza en ACHETSU, Asociación Chilena de Escuelas Universitarias de Trabajo Social. Entonces hay una nueva generación de jóvenes, 40 y pico de años, que está surgiendo con mucha fuerza, que son miembros de esta red de trabajo social crítico internacional y que están ahora tendiendo puentes. El trabajo social en Perú, además de tener una impronta muy fuerte religiosa y católica, es un trabajo social empresarial y gerencial, porque trabajan en empresas fundamentalmente y forman para trabajo social empresarial.

Son características similares, de estos países, con una debilidad muy fuerte en términos de organización a nivel nacional, de organización formal colectiva y con una debilidad de formación terrible, es difícil poder avanzar teniendo conciencia de que queremos y no queremos, qué cosas podemos acordar, debatir teóricamente. Por ahí terminan haciéndose los acuerdos más desde el cariño y el afecto que desde concepciones políticas que acordemos, concepción del trabajo social, así que creo que hay desafíos para la región, creo que hay que volver a instalar debates más políticos del trabajo social. Necesitamos reinventar el trabajo social a nivel regional. Necesitamos atrevernos a construir colectivamente un pensamiento propio. 


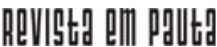

\{ SILVANA NOEMÍ MARTÍNEZ - DINIZ, T. M. R. G.\}

DOI: 10.12957/REP.2021.60311

Hace falta fortalecer y construir liderazgos porque a través de los liderazgos se sostienen estas grandes luchas. Hay que evaluar muchas cosas, hay que evaluar el escenario, las condiciones de posibilidad, pero no perder los espacios, al menos seguir con una región fuerte, que siga disputando y batallando en el ejecutivo mundial y generando alianza con otras regiones, eso es clave".

DOI: $10.12957 /$ rep.2021.60311

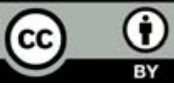

A Revista Em Pauta: Teoria Social e Realidade Contemporânea está licenciada com uma Licença Creative Commons Atribuição 4.0 Internacional. 